\title{
Research on the optimization of industrial structure in Shaanxi Province Based on DEA model
}

\author{
Qunwei Wang ${ }^{1,}{ }^{*}$, Xiujian $\mathrm{Wei}^{2}$, Gangqiang Zha ${ }^{1}$, Shouzhi Xi ${ }^{1}$ \\ ${ }^{1}$ School of Automation, Northwestern Polytechnical University, Xi'an 710072, China \\ 2 School of Economics and Finance, Xi'an Jiaotong University, Xi'an 710061, China
}

\begin{abstract}
The optimization process of industrial structure mainly includes two parts: rationalizing and upgrading industrial structure. Firstly, the $C^{2} R$ model is analyzed through data envelopment. Industrial structure evaluation system consisting of 10 input parameters and 1 output index is established and the industrial structure rationality of Shaanxi Province during 2006-2014 is analyzed. The results show that rationalization of industrial structure in Shaanxi Province is higher. Secondly, the evolution of three industries structure in Shaanxi Province is analyzed. The proportion of the tertiary industry in GDP is compared among the Shaanxi Province, the whole nation, Chongqing, Shanghai and Guangdong. It can conclude that the level of industrial structure upgrading in Shaanxi Province is low, which means the proportion of the tertiary industry is low. In order to solve this problem, relevant measurements are needed to promote the development of the tertiary industry in Shaanxi Province.
\end{abstract}

Keywords: industrial structure; DEA model; optimization research

\section{Introduction}

The optimization of industrial structure is a process from the low stage to the advanced stage. The process includes two parts: rationalizing and upgrading industrial structure. Rationalizing industrial structure refers to adjusting the distribution of resources rationally among various industrial sectors according to the objective proportion relation of technology-related industrial economy, and promoting the development process among various industries of the national economy harmonically. The advanced industrial structure refers to accelerating the industrial structure developing from low-level to high-level through the technological innovation according to the economic development history and evolution law of logic sequence ${ }^{[1]}$. Therefore, the rationalization of industrial structure reflects the objective requirements of the industrial structure, which shows that the development of industrial structure should be compatible with the level of social and economic development in a certain region. The advanced industrial structure reflects the objective needs of industrial structure. The development of industrial structure should follow the general rules of industrial structure development and conform the trend of world industrial development meanwhile. Both are indispensable in industrial structure optimization. Based on the theory of industrial structure optimization, this paper evaluated the rationalization degree of industrial structure in Shaanxi Province quantitatively by using DEA method. At the same time, by comparing with the proportion of the tertiary industry among Chongqing, Shanghai and Guangdong and the whole country, the upgrading degree of industrial structure is analysed.

\section{Rational Analysis of Industrial Structure in Shaanxi Province}

\subsection{The establishment of DEA model}

Data envelopment analysis( DEA) is an efficiency evaluation method proposed by two famous American researchers A.Charnes and W.W.Cooper ${ }^{[2]}$. It is an interdisciplinary field of mathematics, operations research, management science and computer science ${ }^{[3]}$. With DEA method induced to the more complex engineering system evaluation, the production function theory was improved and the artificial error was avoided, and the algorithm was simplified ${ }^{[4]}$. The DEA model defines each evaluation object as a decision-making unit (DMU), and collects all decision-making units together 
to form an evaluation group. The input and output indicators of the evaluation group are used as variables to calculate and analyze, and the ratio between the input and output is utilized to determine the effectiveness of the production frontier or not ${ }^{[5]}$.

DEA has been used in economic development widely. Ma Qiang et al. analyzed the input-output efficiency of industrial system, and put forward the policy suggestion of industrial structure optimization in Jiangsu Province by using the DEA method ${ }^{[6]}$. Yu Yan et. al used DEA model to analyzing Chinese industrial innovation problems, and put forward policy recommendations ${ }^{[7]}$. Dai Yue used DEA method to measure the structural transition effect of industrial sector on economic growth, and analyzed the industrial structure effect with Malmquist-TFP index ${ }^{[8]}$. Li Yang used DEA method to calculate the innovation efficiency and pointed out that the regional industrial structure adjustment was closely related to the technological innovation efficiency, and the two-stage efficiency of R\&D and technological transformation promote each other ${ }^{[9]}$.Wang Xuejun carried out a study on the efficiency of cultural industries in 14 cities and prefectures of Gansu Province by using DEA model, and put forward some suggestions to improve the efficiency of regional cultural industries in Gansu Province ${ }^{[10]}$.

In 1978, W.W. Cooper, A.Charnes et.al proposed the $C^{2} R$ model. The maximum effect of $C^{2} R$ model is to introduce the concept of engineering efficiency into economic multi-input and output system, and to evaluate the relative effectiveness of the decision-making unit of the system, and consequently the relative effectiveness of the system is given. In order to determine the effectiveness of decision-making unit more easily, the concept of non-Archimedes infinitesimal quantity is introduced into $C^{2} R$ model, and the simplex method of linear programming is used to solve $C^{2} R$ model. The solution has the duality, and the input and output method are consistent in the same model. In this paper, $\mathrm{D}$ model is adopted:

$$
\left\{\begin{array}{l}
\min \left[\theta-\varepsilon\left(\sum_{j=1}^{m} s^{-}+\sum_{j=1}^{r} s^{+}\right)\right]=v_{d}(\varepsilon) \\
s . t . \sum_{j=1}^{n} x_{j} \lambda_{j}+s^{-}=\theta x_{0} \\
\sum_{j=1}^{n} y_{j} \lambda_{j}-s^{+}=y_{0} \quad \lambda_{j} \\
s^{+} \geq 0, s^{-} \geq 0
\end{array}\right.
$$

In the formula (1), $m$ refers to input; $s$ refers to output; $\lambda_{j}$ refers to weight coefficients of input and output indicators; $n$ refers to the total number of decision - making units, $D M U_{j}$ refers to the $j^{\text {th }}$ decision-making unit; $s^{+}$is residual variables, which is the underproduction variable; $s^{-}$is slack variable, which is unused resource variables; $\varepsilon$ refers to Non - Archimedes Infinitesimal, a small enough positive number $\left(10^{-6}\right)$ is often used in practice; $\theta$ refers to the relative efficiency of industrial structure optimization. The greater the $\theta$ is, the more reasonable allocation of resources are; on the contrary, the higher the degree waste of resources are.

If the optimal solution of the model is $\lambda^{0}, \mathrm{~s}^{0-}, \mathrm{s}^{0+}, \theta^{0}$, it has the following economic meaning:

If $\theta^{0}=1$ and $s^{0-}=0 、 s^{0+}=0$, it indicates that the DMU is valid and the input and output values are optimal.

If $\theta^{0}=1$ and $s^{0-} \neq 0 、 s^{0+} \neq 0$, it indicates that DMU is weakly effective. That is, if the input reduced, the output can be optimized; if keeping the input unchanged, the output can be increased, and then the whole system is still valid.

If $\theta^{0}<1$, it indicates that the DMU is invalid. In order to make DEA valid, the original input can be adjusted, so $\mathrm{X}_{0}$ can be adjusted to $\mathrm{X}_{0}{ }^{*}$, and keep $\mathrm{Y}_{0}$ unchanged. The smaller the value of the corresponding DMU is, the lower the effectiveness is, so the value of the size of the DMU can be used to evaluate the effectiveness. 
In order to evaluate the profitability of the decision-making unit, it can set $k=\sum \lambda_{j}^{0} / \theta^{0}$, and $k$ is the income of the decision-making unit, which has the following characteristics:

If $k=1$, it indicates that the ratio between the sum of the output weight coefficient of the decision unit DMU and the effectiveness evaluation value is 1 . The DMU's scale returns are unchanged, and the resource combination of the DMU indicators is optimal.

If $k<1$, it indicates that the scale returns of the decision-making unit DMU increased. With the decline of the value, the increase speed of DMU's scale grows. In this model, it can increase the output increase through increase the input.

If $k>1$, it indicates that the scale returns of the decision-making unit DMU decreased. With the increase of the value, the decreasse speed of DMU's scale grows. In this model, the increase in input can not bring about changes in output; therefore, it should not increase the input.

\subsection{Empirical Analysis}

Combining with the research of this paper, the input and output data of the model are taken from the Statistical Yearbook and special fund plan of various industries. The economic development data of Shaanxi Province from 2006 to 2014 is selected and the data in every year is refered as a decision-making unit, and from three industries, a relatively effective evaluation of industrial structure is made from industrial employment, investment and energy consumption. The input index are: employment input (primary industry $\mathrm{x}_{1}$, secondary industry $\mathrm{x}_{2}$, tertiary industry $\mathrm{x}_{3}$, unit: ten thousand people), fixed assets input (primary industry $\mathrm{x} 4$, secondary industry $\mathrm{x} 5$, tertiary industry $\mathrm{x} 6$, unit:one hundred million yuan), the comprehensive energy consumption (primary industry $\mathrm{x} 7$, secondary industry $\mathrm{x} 8$, tertiary industry $\mathrm{x} 9$, unit: ten thousand tons of standard coal), special funds related industry input ( $\mathrm{X}_{10}$, unit: ten thousand yuan); output index: total output value (unit: hundred million yuan).

The DEA model of the industrial structure in Shaanxi Province was calculated by using matlab 2013, and the DEA evaluation results (Table 1) was obtained. The relative efficiency index reflects the difference between the actual input and the optimal output of the three industries in Shaanxi Province in different years, and the larger value express the greater industrial input and output and the higher rationalization degree of the industrial structure. The smaller value express the lower degree of rationalization and greater adjustment and optimization of the industrial structure are needed.

Table 1. DEA evaluation results of industrial structure in Shaanxi Province

\begin{tabular}{|l|l|l|l|l|l|l|l|l|l|l|}
\hline & & 2006 & 2007 & 2008 & 2009 & 2010 & 2011 & 2012 & 2013 & 2014 \\
\hline & & DMU1 & DMU2 & DMU3 & DMU4 & DMU5 & DMU6 & DMU7 & DMU8 & DMU9 \\
\hline $\mathrm{x}_{1}$ & $\mathrm{~s}^{-}$ & 0 & 0 & 0 & 43.7176 & 136.7671 & 0 & 0 & 0 & 0 \\
\hline $\mathrm{x}_{2}$ & $\mathrm{~s}^{-}$ & 0 & 0 & 0 & 22.6316 & 59.1857 & 0 & 0 & 0 & 0 \\
\hline $\mathrm{x}_{3}$ & $\mathrm{~s}^{-}$ & 0 & 0 & 0 & 62.8893 & 91.6009 & 0 & 0 & 0 & 0 \\
\hline $\mathrm{x}_{4}$ & $\mathrm{~s}^{-}$ & 0 & 0 & 0 & 0 & 170.5164 & 0 & 0 & 0 & 0 \\
\hline $\mathrm{x}_{5}$ & $\mathrm{~s}^{-}$ & 0 & 0 & 0 & 0 & 0 & 0 & 0 & 0 & 0 \\
\hline $\mathrm{x}_{6}$ & $\mathrm{~s}^{-}$ & 0 & 0 & 0 & 0 & 0 & 0 & 0 & 0 & 0 \\
\hline $\mathrm{x}_{7}$ & $\mathrm{~s}^{-}$ & 0 & 0 & 0 & 8.3296 & 14.7121 & 0 & 0 & 0 & 0 \\
\hline $\mathrm{x}_{8}$ & & 0 & 0 & 0 & 0 & 0 & 0 & 0 & 0 & 0 \\
\hline $\mathrm{x}_{9}$ & & 0 & 0 & 0 & 56.5612 & 197.4654 & 0 & 0 & 0 & 0 \\
\hline $\mathrm{x}_{10}$ & & 0 & 0 & 0 & 1.1818 & 2.0622 & 0 & 0 & 0 & 0 \\
\hline
\end{tabular}


Table 1, cont.

\begin{tabular}{|l|l|l|l|l|l|l|l|l|l|l|l|}
\hline $\mathrm{y}$ & $\mathrm{s}^{+}$ & 0 & 0 & 0 & 0 & 0 & 0 & 0 & 0 & 0 \\
\hline & $\theta$ & 1 & 1 & 1 & 0.9243 & 0.9507 & 1 & 1 & 1 & 1 \\
\hline & $\mathrm{k}$ & 1 & 1 & 1 & 0.9447 & 0.8613 & 1 & 1 & 1 & 1 \\
\hline
\end{tabular}

From Table 1, it can be concluded that DEA effectiveness evaluation value $\theta$ of Shaanxi industrial structure is equal to 1 in 2006-2008 and 2011-2014, and the values of the slack and residual variables of input and output indicators are all 0. It indicates that the industrial structure of Shaanxi province is DEA effective relatively during the 6 years. But in 2009 and 2010, the DEA effectiveness evaluation value of industrial structure input and output in Shaanxi Province is less than 1. It indicates that the input and output resource allocation of the industrial structure of Shaanxi Province is DEA invalid and the resource allocation efficiency of 2009 is lower than that of 2010. In order to make the DEA effective in 2009 and 2010, the input and output of the model can be adjusted to make the DEA model to be effective according to the projection principle of the dual model of DEA.

Table 2. Input and output adjustment table of industrial structure in 2009 and 2010 in Shaanxi province

\begin{tabular}{|l|l|l|l|l|l|l|}
\hline & \multicolumn{3}{|c}{2009} & \multicolumn{3}{c|}{2010} \\
\hline & $\begin{array}{l}\text { Original } \\
\text { value }\end{array}$ & $\begin{array}{l}\text { After } \\
\text { adjustment }\end{array}$ & Adjust ratio & $\begin{array}{l}\text { Original } \\
\text { value }\end{array}$ & $\begin{array}{l}\text { After } \\
\text { adjustment }\end{array}$ & Adjust ratio \\
\hline $\mathrm{x}_{1}$ & 876 & 766.0 & $12.6 \%$ & 856 & 677.0 & $20.9 \%$ \\
\hline $\mathrm{x}_{2}$ & 493 & 433.0 & $12.2 \%$ & 561 & 474.2 & $15.5 \%$ \\
\hline $\mathrm{x}_{3}$ & 691 & 575.8 & $16.7 \%$ & 657 & 533.0 & $18.9 \%$ \\
\hline $\mathrm{x}_{4}$ & 224.4 & 207.4 & $7.6 \%$ & 487.4 & 292.8 & $39.9 \%$ \\
\hline $\mathrm{x}_{5}$ & 2388.1 & 2207.3 & $7.6 \%$ & 3009.2 & 2860.8 & $4.9 \%$ \\
\hline $\mathrm{x}_{6}$ & 3940.9 & 3642.6 & $7.6 \%$ & 5064.7 & 4815.0 & $4.9 \%$ \\
\hline $\mathrm{x}_{7}$ & 13.1 & 183.6 & $11.6 \%$ & 17.2 & 184.4 & $12 \%$ \\
\hline $\mathrm{x}_{8}$ & 207.6 & 4210.0 & $7.6 \%$ & 209.4 & 4756.9 & $4.9 \%$ \\
\hline $\mathrm{x}_{9}$ & 4554.9 & 2194.0 & $9.9 \%$ & 5003.6 & 2427.2 & $12.1 \%$ \\
\hline $\mathrm{x}_{10}$ & 2434.8 & 10.9 & $16.6 \%$ & 2760.8 & 14.2 & $17 \%$ \\
\hline $\mathrm{y}$ & 8169.8 & 8169.8 & 0 & 10123.5 & 10123.5 & 0 \\
\hline
\end{tabular}

It can be seen from Table 1, the decision-making unit revenue values of 2009, 2010 are 0.9447 , 0.8613 respectively, and they are less than 1 . It indicates that the decision-making unit revenue values is increased. The higher proportion increase of the decision-making unit output can be achieved through appropriate increase of input based on the original investment, and the adjustment results are in Table 2. It can be attributed to the global financial crisis, 4 trillion National investment and the measures taken to stimulate economic development in Shaanxi Province, which breaks the original economic balance. In 2006-2008, 2011-2013 year, the input and output and the industrial structure of Shaanxi province is reasonable and the production efficiency is good; that is, after 2 years' adjustment in 2009-2010, the industrial structure of Shaanxi province has entered a stable balanced point and the economic development has reached a new height andthe total output value exceeded 1 trillion yuan. Thus, it is appropriate to take some measures such as increasing the support of special funds to further promote the economic development of Shaanxi province. In 2006-2008 and 2011-2014, the values of the decision-making unit are 1, it indicates that the the decision-making kept unchanged, and non-revenue resources reached optimal allocation. Even though the efficiency 
evaluation values in 2009 and 2010 are less than 1, their values are all larger than 0.9. It indicates that the industrial resource allocation in Shaanxi is reasonable generally.

\section{Analysis on the advanced Industrial Structure of Shaanxi Province\}

\subsection{The Evolution of the Three Industrial Structures}

After the reform and opening-up, the industrial structures in Shaanxi Province has been adjusted and optimized continuously. The three industrial structures have been changed from "2-1-3 model" (1978-1985) to the "2-3-1" model (form 1986 till now). In 2014, the proportion of the three industries was 8.9: $54.1: 37$. Compared with 1978 , the proportion of the primary industry decreased $22 \%$ and the secondary industry proportion increased $3.5 \%$, and the tertiary industry proportion was more than $35 \%$, with an increase of 18.5 percentage points.

In recent years, Shaanxi's economy has grow rapidly, and the GDP growth rate has entered the country's first aquare. From 2006 to 2014, the basic characteristics of Shaanxi's industrial structure changes are that the proportion of the primary industry decrease gradually, the proportion of the secondary industry rising gradually, and the proportion of the tertiary industry has a slow decline (Figure 1). This feature is in accordance with the economic development stage of Shaanxi. It is in the middle of industrialization and industry is dominant in the national economy.

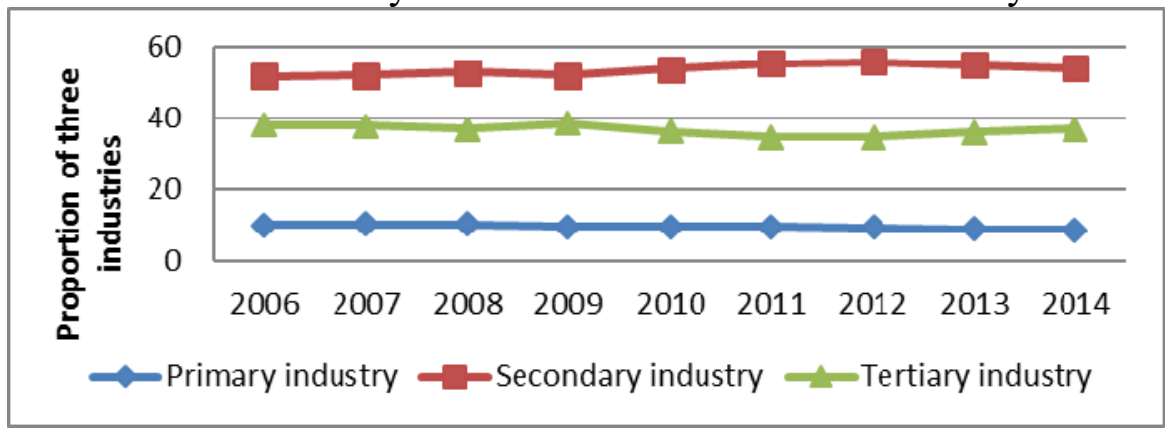

Figure 1. Evolution of the proportion of three industries in Shaanxi Province, 2006-2014

\subsection{Comparison of the proportion of the tertiary industry}

In recent years, due to rapid development of the secondary industry in Shaanxi Province, the proportion of the tertiary industry decreased accordingly. In 2014, the proportion of the primary industry in Shaanxi Province is lower than national total by 0.5 percentages, while the proportion of the secondary industry is higher by 11.6 percentage and the proportion of the tertiary industry is lower by 11.2 percentages. The proportion of added value of the tertiary industry has exceeded that of the secondary industry, while the secondary industry in Shaanxi is still in development. However, comparing with national industrial structure, there is a big gap, indicating that the industrial structure of Shaanxi Province still needs to be optimized. In addition, the proportion of the tertiary industry in Shaanxi Province is also lower compared with Chongqing in west, Shanghai in east, and Guangdong in south (Figure 2), indicating that Shaanxi's development of high-level industrial structure is still inadequate, and further improvement is necessary.

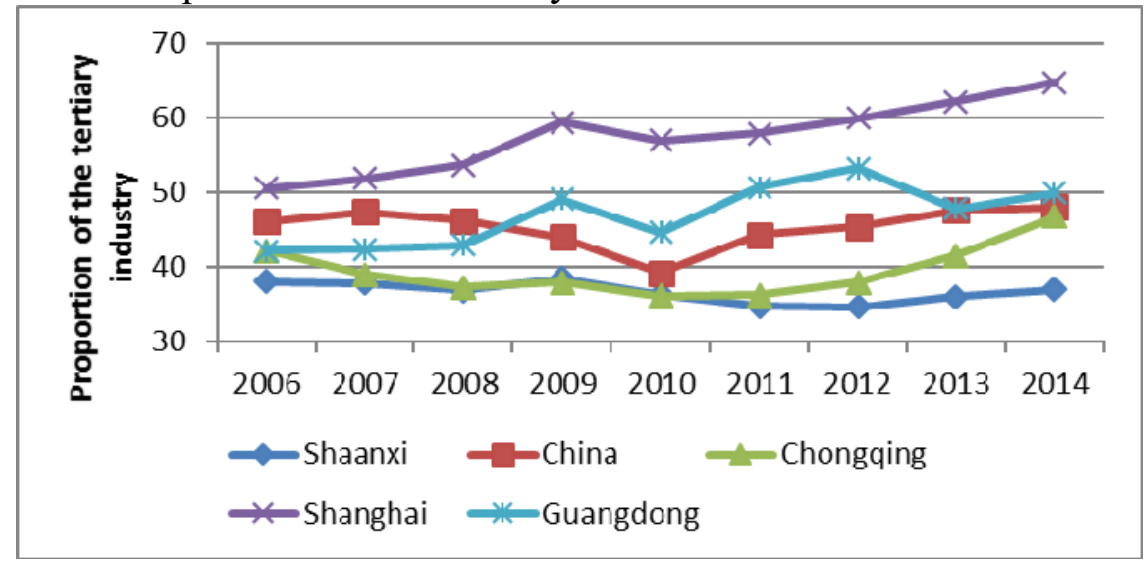

Figure 2. Proportion of the tertiary industry in 2006-2014 


\section{Conclusions}

Rationalization of industrial structure is closely linked with high level of industrial structure. Rationalization of industrial structure provides basis for advanced industrial structure, while advanced industrial structure promotes rationalization of industrial structure to a higher level. Rationalization of industrial structure focuses on short-term interests of economic development, while higher-level industrial structure is more concerned about future growth, focusing on long-term interests of economic development.

From the angle of relative efficiency of industrial structure inputs and outputs, rationalization degree of industrial structure in Shaanxi Province has been at a high level since 2006, only in 2008 some imbalance appeared because of the financial crisis and national macroeconomic policies. But after adjustment, industrial structure is more reasonable.

However, by analyzing the proportion of the industrial structure in Shaanxi Province, the proportion of the tertiary industry is still low. It indicates that advanced industrial structure in Shaanxi Province is low and the existed industrial structure needs to be further adjusted. From the current industrial development in Shaanxi Province, it should pay more attention to create a new point for the Silk Road Economic Zone and establish high ground opportunities for inland reform and opening up. The leading role should be industrial transformation and upgrading demand. And the goal should be to reach high level in the value chain. Meanwhile, the plan should be made scientificly. In the key areas of product services, the key links to find breakthroughs, In the concentration of intensive, it should make breakthrough in the important step, and make development in the advantagous characteristics. It is important to speed up integration of production, information technology, service industry and industrial agriculture. And it should promote economic structural adjustment and optimization and improve quality and efficiency to build new engine for Shaanxi economy. Significantly, it should increase the added value of the tertiary industry among GDP, especially the role of product services to enhance the economy. Thus, it can promote the overall opening function of Shaanxi, comprehensive service capabilities and further enhance the international competitiveness.

\section{References}

[1] GUO Jian-mei, WANG Li. Based on DEA of Dalian Industrial Structure Optimization Evaluation [J]. Resource Development \& Market,2011(4).

[2]WEI Quanlin. Data Envelopment Analysis Model for Evaluating Relative Effectiveness - DEA and Network DEA [M]. Beijing: China Renmin University Press, 2012.6.

[3] MA Zhanxin, MA Shengjun, BAO Siqingaowa. Data Envelopment Analysis and Its Application [M].Beijing: Science Press, 2013.3.

[4] Li Meijuan, Chen Guohong. A Review on the Research and Application of DEA [J]. Engineering Science, 2003.5(6).

[5] Wei Quanling, Cui Yugang. Evaluation of relative effectiveness of several important DEA model-Data Envelopment Analysis (2)[J]. Systems Engineering-Theory \& Practice, 1989.9(2).

[6]Ma Qiang, Lin Wen. Analysis on industrial structural optimization based on DEA in Jiang Su province,[J]. Systems Engineering-Theory \& Practice, 2010(2).

[7] Yu Yan, Sun Minhui. Research on efficiency evaluation method of industrial innovation system based on DEA analysis[J]. Science and Technology Management Research, 2010(2).

[8]Yue Dai,Study on the Structural Change Effect of Economic Growth Based on Industrial Sectors[J].Statistics and Decision,2014(5).

[9]Yang Li,Research on Technology Innovation Efficiency of Regional Industrial Enterprises Based on Network DEA[J].Statistics and Decision,2015(23). 
[10]Xuejun Wang,Space Research on the Impact of Tax Reform on Urban Development[J].Statistics \& Information Tribune,2015(7). 